Fecha de recepción: marzo 2020 Fecha de aceptación: abril 2020 Versión final: mayo 2020
Los victimarios en el cine documental.
El díptico de Joshua Oppenheimer y la
modalidad participativa

Lior Zylberman ${ }^{(1)}$

Resumen: Este trabajo se enmarca en una investigación sobre la representación de los genocidios en el cine documental, en esta instancia se indagará en torno a cómo ha sido presentada la memoria de los victimarios. Para ello, primero se revisará en forma breve algunos antecedentes y problemas sobre el tema; en segundo lugar, repasaremos las estrategias de representación empleadas que sugerimos para analizar la representación del victimario; para finalmente, concentrarnos en la modalidad participativa a partir del análisis de los documentales The Act of Killing (Joshua Oppenheimer, 2012) y The Look of Silence (Joshua Oppenheimer, 2014). Allí, además de pensar las características de esta modalidad, analizaremos la memoria que esta estrategia permite poner en movimiento.

Palabras clave: Cine documental - genocidio - perpetradores - modos - violencia

[Resúmenes en inglés y portugués en las páginas 85-86]

(1) Doctor en Ciencias Sociales. Investigador del CONICET y del Centro de Estudios sobre Genocidio de la UNTREF. Profesor titular de Sociología en la FADU-UBA

\title{
Introducción
}

Este trabajo es parte de una investigación en curso en la que propongo un abordaje que permita pensar, clasificar y definir las diversas estrategias de representación del genocidio en el cine documental. En consecuencia, el presente escrito se propone presentar algunos avances y conclusiones provisorias como también debates generados en el marco de la investigación. Para ello me abocaré a problematizar algunas aristas a partir del díptico documental de Joshua Oppenheimer sobre el genocidio que tuvo lugar en Indonesia durante los años 1965-6 compuestos por los films The Act of Killing (2012) y The Look of Silence (2014). 
Para pensar la representación de los genocidios en el cine documental he sugerido dos ejes, dos ejes que se encuentran vinculados e interrelacionados entre sí: uno, los motivos; el otro, las funciones ${ }^{2}$. Una segunda etapa de la investigación, actualmente en curso, tiene como objetivo continuar con la tendencia metodológica anterior a fin de estudiar uno de los motivos narrativos: el elemento humano, más específicamente los perpetradores. Es en ese marco, entonces, que a continuación me abocaré a presentar algunos debates en torno a la representación de los perpetradores en el cine documental, revisando en forma breve algunos antecedentes y problemas; en segunda instancia, repesaré las estrategias de representación de los victimarios ${ }^{3}$ que he pensado como parte de la investigación; para finalmente, concentrarme en la sugerida modalidad participativa a partir de los films de Joshua Oppenheimer ${ }^{4}$.

\section{La representación del victimario}

$\mathrm{Al}$ examinar las representaciones audiovisuales, la víctima ha sido principalmente el foco de interés en las producciones sobre genocidio, dictaduras y crímenes de masa; y en el cine documental históricamente se ha ido instaurando una "tradición de la víctima" desde la consolidación del cine social de la escuela de John Grierson en la década de 1930 (Winston, 1988). Escapa al presente trabajo dar cuenta de las diversas discusiones y abordajes teóricos en torno a los perpetradores pero lo cierto es que en los últimos años se ha ido desarrollando en forma más sistemática un campo multidisciplinario específico de estudios sobre éstos, siendo el Holocausto el paradigma de análisis y la matriz teórica-conceptual primordial; dicho caso, también ha sido el caso insignia para pensar un "giro al perpetrador" (turn to the perpetrator) en el análisis literario y cultural de esta figura (Adams \& Vice, 2013).

Comúnmente se piensa a los victimarios, sobre todo aquellos quienes han cometido un genocidio, en términos extremos - malvados, sádicos, enfermos, etc.- o incluso como seres ubicados por fuera del mundo humano. Efectivamente, las primeras indagaciones sobre el tema, sobre todo los intentos de estudiar desde la psiquiatría a los nazis acusados en Núremberg, proponían dilucidar la anormalidad de dichos sujetos (El-Hai, 2015) resultando una tarea infructuosa. Posteriormente, los ya clásicos textos de Raul Hilberg (2005) sobre la burocracia nazi y el de Hannah Arendt (2005) sobre Adolf Eichmann, permitieron pensar la "normalidad" o banalidad de los perpetradores; y tiempo después, las investigaciones de autores como Christopher Browning (2011), James Waller (2007), Jean Hatzfeld (2004) o Philip Zimbardo (2008) repararon en la transformación de gente común a genocidas abriendo así un campo de estudio específico. Esos trabajos también permitieron observar que si comúnmente se piensa a los victimarios como seres diabólicos e irracionales se debe a nuestro deseo de no ver en ellos la potencialidad de convertirnos nosotros mismos en victimarios.

Las primeras representaciones de victimarios tuvieron lugar en películas documentales sobre el Holocausto; en esa dirección, las primeras producciones los caracterizaron de modo unidimensional, como seres diabólicos, dejando de lado los matices que existen en este grupo para concentrarse, ante todo, en los ideólogos. Ya en las imágenes de los Juicios 
de Núremberg se modeló esta caracterización que será puesta en tensión y contraste con las imágenes del Juicio a Eichmann. Con todo, durante mucho tiempo, los documentales sobre el Holocausto caracterizaron a los nazis en la forma unidimensional recién mencionada, en títulos como Hitler, Eine Karriere (Joachim Fest y Christian Herrendoerfer, 1977) o Genocide (Arnold Schwartzman, 1982), presentando una abierta reivindicación del papel del individuo en la historia antes que analizar y problematizar los procesos que permitieron el exterminio. Con el tiempo, tanto con la evolución las prácticas y del lenguaje del cine documental como por la investigación académica sobre el tema, la representación de los victimarios fue complejizándose, siendo The Act of Killing signo de ello.

Lo cierto es que al pensar la presentación de los victimarios en el cine documental surgen diversas preguntas éticas: ¿se le debe dar voz e imagen? ¿Qué gana un documental al tener la voz de un victimario entre sus testimonios? ¿Es una prueba que confirma lo que dice el sobreviviente-víctima o puede ser exhibida en forma autónoma sin apelar a otras voces? ¿Se puede llegar a empatizar con los victimarios? Dar la voz al victimario, entonces, plantea otros tipos de problemas éticos, distintos a los que se despliegan al presentar a la víctima. Quizá uno de los rechazos que más genera al ver a los victimarios en la pantalla es, como ya lo señalara Hannah Arendt, su normalidad. Las memorias de varios Einsatzgruppen narradas en Das radikal Böse (Stefan Ruzowitzky, 2013) nos proveen un gran abanico de pensamientos y sensaciones que tenían las tropas especiales, y antes de ser movidos por una necesidad de hacer el mal, su tarea era para ellos ante todo un trabajo. Entonces, $\dot{\iota}^{\text {al }}$ ser retratado, puede el victimario tener pesadillas por sus actos, como Anwar Congo en The Act of Killing? ¿Pueden ser las lágrimas de los campesinos camboyanos otrora cuadros del Khmer Rouge en Enemies of the People (Thet Sambath y Rob Lemkin, 2009) signo de sus traumas y símbolo de arrepentimiento? De ser así, ¿puede expresarse todo ello en el documental? En The Memory of Justice (Marcel Ophüls, 1976), un documental en el cual se recuerdan los treinta años de los Juicios de Núremberg y su continuidad en el mundo de posguerra de aquel momento, se pueden encontrar varias de las aristas antes mencionadas. En el film de Ophüls, además de entrevistar a abogados que participaron en dicho juicio, investigadores, activistas por la paz, ex militares y médicos nazis como también miembros del partido, se entrevista a Karl Dönitz y a Albert Speer: mientras el primero justifica su desconocimiento del genocidio, sorteando las preguntas del realizador, el segundo asume rápidamente la responsabilidad y ante la cámara se arrepiente de lo hecho, pidiendo, en cierto sentido, una redención. El caso de Speer resulta provocativo para pensar hasta qué punto ese arrepentimiento es sincero, profundo, o, finalmente, una personificación. Así, de llegar el victimario a arrepentirse ¿hasta dónde se les cree? ¿cuánto hay de honestidad en sus dichos?

Para ahondar en estas cuestiones, la obra de Rithy Panh se vuelve necesaria de ser mencionada. En su focalización de la historia del genocidio camboyano, el director explora en S-21, la machine de mort Khmère rouge (Rithy Panh, 2003) los diversos matices de lo que fuera el centro de tortura y exterminio de Tuol Sleng. Para examinarlo, Panh convoca no sólo a sobrevivientes como Vann Nath, quien da testimonio con su voz y con sus pinturas, o a Chum Mey sino también a ex guardias y torturadores. Panh reconstruye así la microfísica del funcionamiento de la prisión, haciéndole recrear a los antiguos guardias y tortura- 
dores sus tareas, y a diferencia de la toma de testimonio clásica, gran parte de los registros fueron hechos en la misma prisión convertida en museo. Pero en $\$ 21$... faltaba una figura. Todos los caminos -y los testimonios- conducían hacia una persona en particular: Duch, el antiguo director del centro. En dicho sitio, todas las confesiones arrancadas debían llegar a sus manos y él era el que decidía el "aplastamiento" del detenido. De este modo, Duch, le maître des forges de l'enfer (Rithy Panh, 2011) resulta, si se puede decir así, un mano a mano entre Panh y el victimario. A lo largo de las diversas entrevistas, Duch describe el aparato burocrático asesino, la forma en que eran arrancadas las confesiones, la tortura y también el ideal Khmer Rouge como las expresiones y reglamentos que regían en la prisión. Hombre ya mayor, al momento de filmar la película, Duch se encontraba a la espera del inicio de su juicio en el marco del Tribunal de Camboya; en el metraje, el ex director del S21 no expresa remordimiento o arrepentimiento sino convicción. La pregunta en torno a cómo filmar al perpetrador vuelve a instalarse en este film que, a su vez, tiene la particularidad de ser el suyo el único testimonio. En la experiencia de enfrentarse a Duch, Panh expresó la dificultad y los problemas éticos que lo asaltaron:

Tras cientos de horas de rodaje, vi la verdad con toda claridad: me había convertido en el instrumento de aquel hombre. En cierta medida, en su consejero. Su entrenador. Lo escribí: no busco la verdad, sino el conocimiento. Que se haga la palabra. La de Duch era una cantinela: un juego con la falsedad. Un juego cruel. Una epopeya borrosa. Con mis preguntas, había participado en su preparación para el proceso. Luego, ¿yo había sobrevivido al régimen Khmer Rouge, indagaba el enigma humano en la persona humana de Duch, y él me utilizaba? Esa idea me pareció insoportable (Panh \& Bataille, 2013, pp. 23-24).

Entonces, cómo posicionarse éticamente ante los victimarios. ¿Se los debe respetar del mismo modo que a las víctimas-sobrevivientes? ¿Ante la cámara, poseen los mismos derechos? Al revisar los diversos casos, la respuesta parecería ser que no. Ante los victimarios, sobre todo aquellos que no vacilan en vanagloriar lo hecho ni en mostrar señales de arrepentimiento, el documentalista no puede posicionarse en forma neutral debiendo quizá poner en suspenso la ética del documental. En consecuencia, el engaño parece ser la estrategia primaria de muchos realizadores, ya sea filmando por medio de cámaras ocultas o bien no respetando acuerdos previos. 5 . Otra estrategia empleada es la de "la entrevista en emboscada", que supone mostrar lo que la cámara siguió registrando a pesar de haber cortado aparentemente la filmación: lo vemos en Juan, como si nada hubiera sucedido (Carlos Echeverría, 1987) como también en Escadrons de la mort: L'école française (MarieMonique Robin, 2003). Con todo, la situación de engaño puede resultar un momento de peligro para su realizador; a Claude Lanzmann, por ejemplo, el engaño casi le cuesta la vida $^{6}$. Quizá sean los dichos de Marie-Monique Robin la que mejor sinteticen la posición de todos estos realizadores que a través del engaño o de no cumplir con su palabra o de hacerse pasar por otra persona para alcanzar una declaración, logran que los victimarios expresen lo que niegan en público; así, al referirse a los registros de militares argentinos y chilenos justificando la tortura y la desaparición de personas, al meditar sobre el uso de la cámara oculta en su documental, Robin afirmó: "no tuve ningún problema ético, estaba frente a un victimario, un violador de los derechos humanos"7. Ante el victimario, entonces, parecería no haber código ético prestablecido ya que en tanto victimario ha perdido 
la posibilidad de gozar de los derechos sobre su imagen del mismo modo en que los disponen las víctimas-sobrevivientes. De este modo, si las prácticas éticas del cine documental solicitan un buen trato a las personas filmadas, al registrar a victimarios los documentales ponen en tensión los límites posibles de dichas prácticas.

\section{Modalidades de representación del victimario}

A continuación, propongo distinguir cuatro modalidades en que el victimario ha sido representado en el cine documental. Éstas no esperan ser normativas ni taxativas sino ser pensadas como tendencias, como estrategias de representación; en ese sentido, como se verá, un documental puede tender hacia una modalidad en particular como transitar por varias a la vez.

La primera modalidad la denomino Archivo, contemplando así lo que comúnmente se refiere como material de archivo o imágenes de archivo; es decir, registros visuales tomados originalmente por alguien para luego ser editados y montados para crear una determinada película. En esta modalidad predominan dos fuentes de imágenes: el registro de los propios victimarios en su tarea -ya sean tomadas por ellos mismos como por otros- o filmaciones generales que no remiten necesariamente al exterminio -por lo general resultan ser películas de propaganda, noticieros cinematográficos o televisivos o incluso también generadas por los propios victimarios-. Los títulos que prevalecen en esta modalidad son asociados con los documentales de compilación o bien aquellos que emplean imágenes de archivo para ilustrar el relato histórico que presentan. En ocasiones, las imágenes de archivo son montadas en forma alternada con entrevistas, constatando lo que el entrevistado afirma o bien otorgándole un sentido, a partir de la entrevista, a dichas imágenes. En esta modalidad el victimario no tiene la palabra, y si la brinda no es específicamente para la cámara documental. Aquí, entonces, el victimario es representado en forma silente, no se expresa en forma libre, no es su voz la que escuchamos, sino que otro habla por él. Documentales como Nuremberg. Les nazis face à leurs crimes (Christian Delage, 2006), Un spécialiste, portrait d'un criminel moderne (Eyal Sivan, 1999), Los 100 días que no conmovieron al mundo (Vanessa Ragone, 2009), The Uncondemned (Nick Louvel y Michele Mitchell 2015), Un claro día de justicia (Ana Cacopardo e Ingrid Jaschek, 2006) o Brother Number One (Anne Goldson y Peter Gilbert, 2012) pueden ser pensados bajo esta modalidad.

La segunda modalidad para representar al victimario la denomino Evocativa. La evocación es una forma de traer a la imaginación, una llamada o convocatoria para que algo $o$ alguien se haga perceptible. Es en el marco de una entrevista-testimonio que surge la evocación, la figura del victimario; allí, éste es delineado y caracterizado por la palabra de otro, siendo comúnmente la víctima-sobreviviente quien suele evocar y distinguir a esta figura a partir de su palabra. En esa dirección, en numerosos documentales el victimario es evocado en forma amplia para referirse a "los SS" en varios documentales sobre el Holocausto, o como hace Graciela Daleo respecto a la "patota" en Cazadores de utopías (David Blaustein, 1996) o algunos sudaneses respecto a los Yanyauid en Darfur en The 
Devil Came on Horseback (Ricki Stern y Annie Sundberg, 2007). Pero la evocación no sólo la realizan los sobrevivientes, sino también expertos -historiadores como David Chandler en S-21: Inside Pot Pot's Secret Prison (Greg DeHart, 2002)-, o bystanders, testigos ocasionales, gente que les brindó asilo y ayuda como también cazadores de nazis. Una producción paradigmática de esta modalidad bien podría ser Hotel Terminus. The Life and Times of Klaus Barbie (Marcel Ophüls, 1988), documental que gira en torno a la figura del llamado "Carnicero de Lyon". En este documental, el victimario es la figura central, sin embargo nunca dio una entrevista ni participó en forma activa para la cámara de Ophüls. La evocación es también la modalidad empleada como forma de elaborar el pasado familiar por algunos hijos de victimarios. En 2 oder 3 Dinge, die ich von ihm weiß (Malte Ludin, 2005), su director, quien es el hijo de Hanns Ludin, miembro de las SA y embajador alemán en la República Eslovaca, bucea en el legado familiar y la figura de su padre al cual casi no conoció ya que fue ejecutado en 1947 cuando tenía apenas cinco años de edad. En conclusión, en esta modalidad, el victimario tampoco se expresa por su propia voz, sino que es caracterizado y representado en la pantalla a través de segundos.

La tercera modalidad la denomino Declarativa. Entiendo por declaración a un anuncio, a una manifestación de hechos, sucesos, conductas o pareceres en un determinado contexto, pero, en el caso de esta modalidad, se refieren a las declaraciones efectuadas específicamente para el documental en cuestión. En esta modalidad, el victimario se expresa por sí mismo y aparece frente a la cámara del documentalista. Con todo, esta modalidad no resulta necesariamente "apacible", alcanzar la declaración de un victimario no suele ser una tarea sencilla; por lo tanto, esta modalidad también contempla otras tácticas llevadas adelante por los realizadores para registrar -o no- las declaraciones de los victimarios. Einsatzgruppen, les commandos de la mort (Michaël Prazan, 2009), Shoah, Escadrons de la mort: l'ecole française o Noces rouges (Lida Chan y Guillaume Suon, 2012) son algunos de los títulos que integran esta modalidad. En el marco de las declaraciones de los victimarios, hay que tener en cuenta una cuestión nodal: las declaraciones siempre son posteriores a los hechos; es decir, resulta difícil obtener declaraciones de los victimarios -incluso indagar sus motivaciones, sus razones, sus transformaciones de "persona común" a asesino en masa- mientras los crímenes se llevan adelante. En consecuencia, la palabra -o el silencio- del victimario siempre será una cuidadosa elaboración que intentará desligar su responsabilidad transfiriéndola ya sea a colegas o a superiores, o bien al contexto. Por lo tanto, en esta modalidad resulta meditar en torno a qué información aporta su palabra, cómo se posiciona en términos de responsabilidad ante los crímenes y cómo ve y evalúa sus crímenes. En otras palabras, ¿qué recuerda y qué memoria construye el victimario? Finalmente, la última modalidad sugerida es la Participativa. Ofrecer una entrevista es, desde ya, una forma de participar; sin embargo, no es esa la condición que primará en esta modalidad. Aquí, la participación se refiere a cuando el victimario se dispone a actuar, a recrear, ante la cámara. Es por eso que los documentales que apelan a esta modalidad son escasos e infrecuentes, pero cuando recurren a ésta, suelen traer consigo discusiones de diversos tipos. El mocito (Marcela Said y Jean de Certeau, 2011), película que sigue a Jorgelino Vergara ${ }^{8}$, puede ser pensada en el marco de esta modalidad. También Mr. Death (Errol Morris, 1999), que combina la recreación hecha con actores como con el propio Fred Leuchter, el negador del Holocausto protagonista del documental, o Enemies of the 
People, donde Suon muestra, cuchillo en mano, cómo cometió uno de los asesinatos. En S-21... Rithy Panh convocó a ex guardias y sobrevivientes del centro de tortura y muerte, mostrando uno de los guardias lo que hacía en una de sus rondas. En todos estos títulos, la participación es actuada por el propio victimario pero en un número de escenas o secuencias acotadas. En cambio, en The Act of Killing y, en menor medida, en The Look of Silence, la recreación es el recurso principal.

El díptico de Joshua Oppenheimer podría, entonces, erigirse como el paradigma de la modalidad participativa. Esto hace que surjan diversas preguntas, sobre todo aquellas relacionadas con el conocimiento que permite el empleo de esta modalidad. Para decirlo de otro modo, la pregunta no sería solamente por qué optó su director esta modalidad sino también qué nos permite conocer respecto a la violencia genocida estos documentales.

\section{The Act of Killing y The Look of Silence como paradigmas de la modalidad participativa}

Al preguntarse cómo y en qué condiciones puede el historiador conocer el pasado, R. G. Collingwood escribió que el pasado "nunca es un hecho dado que podamos aprehender empíricamente mediante la percepción (...) el historiador no es un testigo ocular de los hechos que desea conocer" (Collingwood, 1952, p. 323); y si para escribir la historia el historiador debe "re-crear el pasado en su propia mente", el documentalista que apela a la modalidad participativa tiene la posibilidad de que el pasado sea re-creado por los propios protagonistas para su cámara. Así, resulta sugerente pensar y colocar en tensión cuánto de "re" -en tanto volver a, reproducir- poseen dichas actuaciones ante la cámara o bien si son efectivamente nuevas creaciones.

Para un victimario no resulta sencillo dar testimonio de los crímenes que cometió, sobre todo "cuando eres un antiguo torturador. La respuesta que obtienes con mayor frecuencia es 'sí, bueno, fui torturador, pero seguí órdenes”, meditó Rithy Panh; con todo, para este director no se puede avanzar por esa dirección ya que "lleva tiempo hacer que las personas entiendan que para ellos dar testimonio es también responsabilizarse. No hay otro camino. Si quieres volver a la humanidad, entonces tienes que testificar. El peor torturador es el que no reconoce su acto hasta la muerte" (Oppenheimer, 2012, p. 246). Por ende, la tarea del director es crear las condiciones más favorables para esos testimonios, para que las declaraciones de esos testigos se hagan (...) entonces, cuando se habla de destrucción y reducción al polvo, estas no son solo palabras, también hay gestos detrás de estas palabras. Entonces, cuando las palabras no son suficientes, la imagen detrás de las palabras te da la fuerza de los gestos, de los actos (Oppenheimer, 2012, p. 246).

En otras palabras, la participación activa de los victimarios en los documentales, recreando sus crímenes -en ocasiones a partir de elaboradas puestas en escenas- puede permitir que se descubra otra memoria: la corporal. Para el proyecto desarrollado en Indonesia, que le consumió a Joshua Oppenheimer casi una década, el director entendió su trabajo como la búsqueda de una actuación arqueológica que implicó trabajar sucesivamente con y a través de los gestos, rutinas y rituales que fueron el motor de las masacres, así como los géneros y gramáticas de su recuento histórico, que generalmente se trasladan desde la 
entrevista y la recreación con los actores históricos (...) hasta los resúmenes de los eventos relacionados en las entrevistas (Oppenheimer \& Uwemedimo, 2012, p. 304).

De este modo, muchas de las puestas en escena resultan recreaciones de películas de gangsters ya que con ese vestuario los criminales se sienten a gusto para narrar cómo mataban y entonar las mismas canciones que cantaban en el momento en que emprendían la tarea. Como amante del cine, Anwar Congo, protagonista de The Act of Killing pasaba en su juventud tiempo en las salas de cube, y la sala misma a la que el asistía se convirtió en lugar de reclutamiento de gangsters -nombre con el que se autodenominaban los escuadrones de asesinos-; de hecho, el gobernador de Sumatra Septentrional presenta en el film a Anwar como perteneciente al "grupo paramilitar del cine Medan". Asimismo, como narra en la película, al terminar una función Anwar solía cruzar la calle para dirigirse a su "oficina" a interrogar y matar. De joven, nos comenta, veía películas de gangsters, películas violentas, y veía "formas geniales de matar" y las copiaba. De estas le gustaba como empleaban el alambre como arma homicida; de allí que tomara este material como método "para matar comunistas". También le gustaban los musicales, y como forma de celebrar -y anular su conciencia- Anwar solía bailar -además de alcoholizarse y drogarse- luego de cumplir su tarea.

Esta "inspiración" en el cine por parte de Anwar nos señala una relación particular entre imaginación, cine y violencia: de sus dichos puede inferirse el lugar importante que ocupa el cine en el establecimiento de la imaginación violenta. Esto no significa que Anwar, o cualquier otro, se hayan transformado en asesino a causa del cine, pero nos advierte el rol fundamental de las películas en la institución de los imaginarios criminales. Como señala el propio director, el cine "ha dado forma no solo a la violencia política, desde la tortura hasta la guerra y el genocidio, sino también a la forma en que se lleva a cabo" (Brink \& Oppenheimer, 2013, p. 1). El cine desafía los límites de la imaginación de los asesinos, tanto que cuando Anwar mira una película hecha "para odiar a los comunistas", exclama que él fue más allá de lo que se ve en la película.

Al recurrir a una modalidad participativa The Act of Killing logra conjugar el testimonio con la recreación pero en otro nivel: podríamos afirmar que retoma la senda de la estilización iniciada por Errol Morris en sus documentales pero no para asemejarse a ella . En la película de Oppenheimer hay así al menos dos tipos de recreaciones: aquellas que buscan parecerse al hecho pasado, como la primera del film, donde Anwar observa cómo la milicia irrumpe en una casa buscando matar a los comunistas; y las filmadas en forma más estilizada, en un estudio o en las locaciones donde sucedieron los hechos, con el propio Anwar como actor. Lo cierto es que ambos tipos de recreación cuentan con una característica primordial: son los propios asesinos quienes actúan el rol de asesinos. Mientras que con las primeras se busca una semejanza a los acontecimientos pasados -lo vemos, por ejemplo, cuando Herman Koto, compañero de Anwar, le señala a una mujer como debe reaccionar con el objetivo de parecerse a la víctima-; en las segundas, donde en ocasiones se bordea lo kitsch, se pretende bucear por el imaginario de Congo: es el propio protagonista quien organiza las escenas a recrear, quien "dirige" la película junto a Oppenheimer, y con estas puestas, en ocasiones alegóricas, el realizador de The Act of Killing no hace sino llegar al imaginario del asesino. Así, el propio Anwar Congo actúa en las recreaciones de algunos de sus asesinatos, mostrándonos su técnica y contándonos como se sentía y qué pensaba. 
Quisiera entonces detenerme en dos secuencias donde los victimarios indonesios recrean sus crímenes. Una es de The Act of Killing y sucede en la terraza de un negocio donde Anwar Congo re-crea una de sus formas de matar y la otra, que forma parte de The Look of Silence, es la secuencia filmada en el 2003, en los inicios del proyecto, donde Amir Hassan e Ingor vuelven al Snake River para recrear sus crímenes y el asesinato de Ramli Rukun.

En cierto sentido, en ambas secuencias se produce la experiencia del "aquí fue" de Simon Srebnik, sobreviviente del campo de exterminio de Chelmno y primer testimoniante en Shoah, pero a la inversa: el que afirma el aquí fue es el victimario. Por lo tanto, el lugar, el contexto, tendrá un rol fundamental en la recuperación de los recuerdos de estas tres personas. En ambas secuencias, los victimarios poseen perfecta conciencia y conocimiento de la cámara: muestran sus "habilidades", miran a ella, saben que son vistos y saben que serán vistos. Por lo tanto, en esas escenas, que además poseen una extensa duración, los actores sociales llevan adelante una verdadera performance. Utilizando aquí las diversas traducciones al español de dicha palabra, Anwar Congo, Amir e Ingor, actúan, interpretan, ejecutan y realizan su acto criminal para la cámara. Como señalaron Oppenheimer y Uwemedimo, hay una formalidad peculiar en la presentación de Amir. Al igual que cualquiera que se jacta ante la cámara, Amir es consciente de la cámara, y en esta autoconsciencia decorosa, su actuación se vuelve más intensa, explícitamente teatral. Y así, enfocado a través de la lente de la cámara, convergen dos sentidos de performatividad: existe el performativo en el sentido de JL Austin por un lado (...) y performativo como 'teatral', por otro (Oppenheimer \& Uwemedimo, 2012, p. 294).

La performance como un tipo de acting, se puede asociar a los modos en que Dominick LaCapra analizó la noción freudiana de acting out. Si bien resulta un término complejo, el mismo sugiere la emergencia de lo reprimido, y para LaCapra implica "aceptar el trauma, incluidos sus ínfimos detalles, y combatir de manera crítica la tendencia a ponerlo en acto, reconociendo incluso que el acting out puede ser necesario y, en ciertos aspectos, conveniente o imperioso al menos" (LaCapra, 2005, p. 156). Asimismo, además de pensar el trauma desde esta perspectiva también lo hace desde la noción de elaboración; de este modo, acting out y elaboración serían dos formas de sobrellevar el trauma. Mientras que el acting out entraña una repetición compulsiva, la elaboración implica repetición pero con una diferencia significativa, "que puede ser conveniente en comparación con la repetición compulsiva” (2005, p. 161). La elaboración exige volver sobre los problemas, repasarlos y, quizá, "modificar la comprensión que uno tiene de ellos. Aun cuando los problemas hayan sido elaborados, pueden volver y requerir una nueva elaboración, distinta de la anterior tal vez" (2005, p. 161). Ahora bien, el planteo de LaCapra, pensado para una aproximación empática por parte del historiador, se vincula con el contacto entre este profesional y la víctima del trauma -en su caso, los sobrevivientes del Holocausto-. En consecuencia, el acting out del victimario de la modalidad participativa permite poner en discusión la posibilidad de pensar el trauma del perpetrador. ¿Cuál es su trauma? ¿Cómo lo expresa? O, en todo caso, ¿qué es lo que no expresa? ¿Cómo relaciona su trauma con la responsabilidad? ¿Se ve responsable?

Lo cierto es que la participación, la actuación del victimario para la cámara, puede resultar una verdadera herramienta de elaboración para el victimario y de ello dependerá su po- 
sición frente al evento como también la forma en que el público reaccione frente a sus acciones. Mientras que los victimarios de Rithy Panh de S21... o los de Enemies of the People muestran cierto remordimiento, incluso una comprensión de la responsabilidad de sus actos, los de The Look of Silence se muestran orgullosos de sus crímenes. En consecuencia, en su repetición ¿qué tipo de elaboración efectúan? Resulta así sugerente el trayecto de Anwar Congo en The Act of Killing, donde al verse actuar parecería sentir "algo", pudiendo el espectador pensar que antes que un sentido remordimiento y toma de conciencia de su responsabilidad, Congo observe instantes de responsabilidad.

Con todo, la modalidad participativa posee algunos añadidos más que deben ser pensado en dos niveles que operan al mismo tiempo: la memoria y el cuerpo. Por un lado, al ofrecernos sus testimonios y sus recuerdos de sus años como asesinos, The Act of Killing $y$ The Look of Silence presentan las memorias de los victimarios en el sentido de ofrecer un relato coherente sobre el pasado. En ese nivel, las películas no difieren respecto a las que apelan a la modalidad declarativa ya que dichos recuerdos por lo general serán o bien exculpatorios o bien apologéticos del régimen que causó los crímenes. Asimismo, y para el caso de Indonesia, la posibilidad de hablar abiertamente y de revindicar los asesinatos -sobre todo como se ve en The Look of Silence- permite comprender que la memoria de los victimarios se constituyó de ese modo ya que fue construida desde la impunidad, sin juicios ni revisión oficial de los acontecimientos. Sin embargo, hay un elemento más que aporta la modalidad participativa en términos de memoria: aquí ya no estaríamos solamente frente a una memoria que expresa un relato sino que también ante cuerpos que se expresan.

Desde los aportes de la psicología de la memoria y la neurociencia, sabemos que la memoria, y por ende el acto de recordar, es un proceso incesante y no un depósito de información. Todo acto de recuerdo es un acto de creación, el pasado es siempre presente y nuestros recuerdos, por más que parezcan verdaderos y vívidos, se adaptan y modifican a las necesidades del presente. Esta cuestión, entonces, resulta un elemento fundamental al momento de analizar los testimonios, tanto de víctimas como de victimarios. Ahora bien, a partir de las reflexiones de los documentalistas antes citados, la modalidad participativa no sólo es un testimonio verbal sino también corporal, modificando así uno de los núcleos del testimonio. Si en el testimonio, tal como sugirió Simone Veil, la premisa del relato es "estuve allí y eso fue así" (Jablonka, 2017, p. 108), en las películas analizadas en esta modalidad no sólo se reproduce dicha premisa sino que se suma una más, que se podría definir como "yo hice esto, yo lo hago". No se trata solamente de recrear ante la cámara sino, y sobre todo aquellos documentales donde la recreación se da en el lugar donde sucedieron los hechos, del tipo de memoria que se activa: una "memoria dependiente del contexto" (Baddeley et al., 2018, pp. 252-253). La relación entre contexto y memoria resulta importante, ya que cuando los contextos espaciales, temporales, emocionales, fisiológicos o cognitivos que permiten la recuperación de los recuerdos se corresponden con los de su codificación otorgan un beneficio especial a éstos, ayudando no sólo en su recuperación sino a que los recuerdos resulten más vívidos para quien recuerda. En consecuencia, en esos documentales, en las secuencias mencionadas, los victimarios no recuerdan solamente cómo asesinaban; al recrear sus crímenes, los crean, accionan: ante la cámara simulan matar, pero el recuerdo es experienciado como una acción presente. En otras palabras, el cuerpo del victimario no imita su crimen, sino que lo efectúa en el presente. 
Esta forma de trabajar la memoria de los victimarios lleva adelante una operación singular: el propio Oppenheimer señaló que la recreación funciona como una verdadera herramienta de investigación que en vez de presentar "evidencia forense" nos adentra en la imaginación de los victimarios. Dicha herramienta -emplear la modalidad participativa, podríamos decir- es de vital importancia para "comprender los procedimientos imaginativos por los cuales los seres humanos se persiguen entre sí, y cómo luego construimos (y vivimos) sociedades fundadas en violencia sistemática y duradera"10.

Señalé previamente que numerosos documentales lograron la declaración de victimarios, pero ¿acaso la declaración no permite también adentrarse en el imaginario del victimario? El imaginario social remite a los modos en que las personas "imaginan su existencia social, el tipo de relaciones que mantienen unas con otras, el tipo de cosas que ocurren entre ellas, las expectativas (...) y las imágenes e ideas normativas más profundas que subyacen a estas expectativas" (Taylor, 2006, p. 37); en consecuencia, éste parecería quedar plasmado en las declaraciones. Sin embargo, en la modalidad participativa empleada por Oppenheimer hay al menos dos elementos más que permiten llevar adelante la exploración del imaginario. Por un lado, y en ello se emparentan las películas con las de la modalidad declarativa, escuchamos la palabra de los victimarios -que no sucede por medio de engaños o limitadas de antemano- que ejecutaron los crímenes sino también de cuadros superiores -como los líderes del movimiento paramilitar Pancasila- que ordenaron y justificaron los crímenes. Pero por el otro lado, y esa es la novedad, en las propias recreaciones, los victimarios crean sus propias imágenes sobre ellos, nos muestran cómo quieren que sean vistos y entendidos. En la intersección de ambos recursos se asienta también un imaginario de la impunidad: ellos pueden hacer lo que hacen porque se sienten victoriosos, porque saben que no serán juzgados, porque hay un Estado que los cobijó y los señaló como héroes antes que genocidas.

Exponer el imaginario de la impunidad supone también modificar un paradigma, una tradición, tanto del documental como la propia forma en que se han construido los abordajes académicos sobre el tema: la ya mencionada "tradición de la víctima". Desde la constitución de la "era del testigo" (Wieviorka, 2006), el sobreviviente-víctima ha sido la figura ética y de escucha legitimada. ¿Por qué, entonces, el giro hacia el victimario que efectúa Oppenheimer? Comúnmente lograr la declaración de una víctima o sobreviviente resulta sencilla, pudiendo ser pensada su entrevista como un momento de cierta confianza y seguridad, es decir, no implica riesgo físico o de vida; el peligro, en cambio, asomaría al momento de entrevistar a un victimario. El caso de Indonesia resulta un contraejemplo. Si bien el interés inicial de Oppenheimer fue entrar a la historia del genocidio a través del testimonio de las víctimas, filmarlos a ellos resultaba peligroso y se encontraron con numerosos obstáculos no así para filmar a los asesinos. En consecuencia, la ausencia de la víctima, sobre todo en The Act of Killing, no se debe a una mera decisión de dirección, sino que es un signo de la violencia contemporánea en Indonesia. En otras palabras, el díptico trata sobre la violencia pasada, pero son documentos sobre la continuidad de la violencia, esa violencia del pasado es entonces la violencia del presente. 


\section{A modo de cierre}

La representación de los victimarios en el cine documental, sobre todo aquellos que optan por la modalidad participativa, trae interrogantes éticos. No se trata solamente de la pregunta en torno a la posibilidad de darle voz e imagen a un asesino y cómo debe ser presentada, sino también qué gana un documental al tener la voz de un victimario entre sus testimonios.

Es por eso que el díptico sobre Indonesia de Joshua Oppenheimer constituye un caso límite en el cine documental y en lo que a representación de victimarios se refiere. Ambos títulos significan un cambio radical de perspectiva y estética, y por eso llegaron a ser criticadas y señaladas, entre otras cosas, como snuff movies (Fraser, 2013, 2014). Con ello, y a pesar de ello, no debe dejarse de pensar que filmar a victimarios -ya sea en su modalidad declarativa como participativa- resulta ser una situación de peligro constante ${ }^{11}$, poniéndose en tensión la propia pericia y capacidad del documentalista como también su posición ética y sus propios temores.

Como observación final se podría decir que ver y escuchar a los victimarios ayuda a por lo menos tres cuestiones: a confirmar las características del exterminio, a saber qué idea e imaginario construyó el perpetrador sobre la víctima y, finalmente, a vislumbrar qué imagen construyeron de sí mismos. En este sentido, The Act of Killing y The Look of Silence nos permiten indagar en el imaginario de los asesinos ya que lo central no es saber si las recreaciones resultan semejantes a los hechos pasados sino explorar la conciencia de los criminales, de allí el interés por preguntarnos qué tipo de memoria se activa en las recreaciones que llevan adelante. Pienso así que las recreaciones funcionan más como una herramienta para explorar los "paisajes mentales" de los asesinos que como reconstrucción verídica tendiente a una función evidencial. Al indagar sobre la obra de Errol Morris, Carl Plantinga sugirió que en sus las películas las entrevistas tratan sobre "el contenido y las motivaciones de las creencias de las personas", haciendo un uso estratégico de este recurso "porque está fascinado por los paisajes mentales de sus sujetos" (Plantinga, 2009, p. 49). Siguiendo esa línea de pensamiento, se puede decir que las recreaciones, la participación activa de los victimarios en las películas, implica una investidura del personaje en su creencia, siendo su "paisaje de ensueño (dreamscape), su mundo subjetivo, lo que está en cuestión” (2009, p.49).

En The Act of Killing $y$ The Look of Silence la participación es una forma de exhibir la impunidad y la no asunción de responsabilidad, la ostentación de la violencia les permite referirse no sólo al pasado sino, sobre todo, al presente. No recuerdan para ir hacia atrás en el tiempo, sino que esa misma violencia -ejercida quizá de otro modo- la siguen desplegando en el presente. En consecuencia, los documentales que logran la declaración y participación de los victimarios se colocan no sólo como un modo específico de narrar y representar tanto el pasado como el presente sino también como una importante herramienta de investigación y reflexión sobre éstos, presentados ni como demonios ni como "banales", sino, como sugiere de Swaan (2015), simplemente como personas, iguales, diferentes y distintas como todos los demás. 


\section{Notas:}

1. Antigua colonia holandesa, Indonesia obtuvo su independencia en 1945. Fue Sukarno el líder de aquella gesta, y su primer presidente. Ante el creciente apoyo del Partido Comunista de Indonesia (PKI) y lo sconstantes enfrentamientos con las fuerzas armadas, Sukarno fue girando su gobierno hacia uno más autoritario. Con el correr del tiempo, el PKI, el primer partido comunista de Asia, se convirtió en el mayor partido comunista luego de los de la Unión Soviética y China. Las tensiones en ambos frentes llevaron a que Sukarno fuera derrocado en un confuso golpe militar en septiembre de 1965. En consecuencia, el general Suharto se alzó con el poder iniciando el denominado Nuevo Orden que lo llevaría a mantenerse en el cargo de presidente hasta 1998. A poco de iniciarse este nuevo régimen, se produjo la persecución y eliminación sistemática de los comunistas, de todo aquel sospechado de comunista o de brindar apoyo a éstos, como también de los chinos comunistas. Para un desarrollo mayor de la historia, véase Chalk y Jonassohn (2010), Roosa (2006) y Robinson (2018).

2. Un desarrollo mayor puede encontrarse en Zylberman (2018).

3. Término muy discutido el de perpetrador, véase Williams \& Buckley-Ziste (2018), tanto en la investigación que llevo adelante como en esta presentación opto por referirme al término victimario ya que, siguiendo a Jeremy Metz (2012, pp. 1037-1038), dicha expresión "determina fácilmente a su objeto, la víctima" mientras que "perpetrador hace la pregunta de qué se está perpetrando, oculta la condición necesaria del acto de perpetración de tener un objeto, es decir, no hay un equivalente exacto automático para "perpetrado" (perpetratee).

4. Como luego se verá, ambas películas supusieron un giro en la representación de los genocidios ya que presentan el caso desde la voz de los victimarios. The Act of Killing a partir de Anwar Congo, quien no sólo permite reconstruir cómo fueron las matanzas de la década de 1960 sino que junto a otros "compañeros" recrea para las cámaras su metodología asesina como varias situaciones criminales. The Look of Silence continúa dándole voz e imagen a los victimarios pero esta vez a partir de la confrontación entre Adi Rukun, hermano de una víctima, y los responsables de su muerte. He analizado, en forma general, ambas películas en otros trabajos, véase Zylberman $(2015,2016)$.

5. En Santiago, Italia (Nani Moretti, 2018) se produce una curiosa muestra de la imposibilidad de efectuar un pacto. Moretti entrevista a numerosos ciudadanos chilenos que se exiliaron en Italia luego del golpe de Estado de 1973 y a algunos militares actualmente encarcelados, como Eduardo Iturriaga. Al dar Iturriaga su versión de los hechos, exculpando a los militares por la tortura y desaparición de personas, la película hace un corte abrupto donde por única vez se lo ve a Nani Moretti delante de la cámara. En esa toma el militar se muestra enfurecido ya que pensaba que la entrevista iba a ser objetiva e imparcial, Moretti lo mira, escucha al traductor, y le dice a éste que le diga a Iturriaga: "Yo no soy imparcial". 6. Para Shoah (1985) Lanzmann intentó registrar el testimonio de algunos ex Einsatzgruppen pero al filmar con cámara oculta a Heinz Schubert, su familia se dio cuenta y luego de un episodio de violencia física, donde Lanzmann acabó en el hospital, la familia interpu- 
so una orden judicial que prohibía a Lanzmann acercarse a Schubert. Al respecto, véase Lanzmann (2011, pp. 458-463).

7. Véase la entrevista a la directora en "Los métodos de Argel se aplicaron aquí. Entrevista a Marie Monique Robin”, Página/12 edición del 13 de octubre de 2004. Recuperado de https://www.pagina12.com.ar/diario/espectaculos/6-42243-2004-10-13.html [fecha de consulta 19 de octubre de 2019].

8. A los 16 años, Vergara trabajó como doméstico en la casa de Manuel Contreras, director de la DINA, para luego pasar como asistente al "cuartel Simón Bolívar" el único centro de exterminio de la dictadura chilena; allí, presenció y participó en diversas sesiones de tortura. 9. Resulta preciso señalar que Errol Morris actuó como uno de los productores ejecutivos del díptico de Oppenheimer.

10. Declaración de Joshua Oppeneheimer en el folleto de la edición en DVD de The Acf of Killing.

11. Recordemos que la filmación con cámara oculta a Heinz Schubert, antiguo miembro de los Einsatzgruppen nazis, casi le cuesta la vida a Claude Lanzmann, debiendo terminar hospitalizado y prohibiendo un juzgado alemán el uso de esa filmación (Lanzmann, 2011).

\section{Bibliografía}

Adams, J., \& Vice, S. (Eds ). (2013). Representing Perpetrators in Holocaust Literature and Film. Vallentine Mitchell.

Baddeley, A., Eysenck, M., \& Anderson, M. (2018). Memoria. Alianza Editorial.

Brink, J., \& Oppenheimer, J. (2013). Killer Images: Documentary Film, Memory and the Performance of Violence. Columbia University Press.

Browning, C. (2011). Aquellos hombres grises. El batallón 101 y la solución final en Polonia. Edhasa.

Bruzzi, S. (2006). New Documentary. Routledge.

Chalk, F., \& Jonassohn, K. (2010). Historia y sociología del genocidio. Prometeo.

Collingwood, R. G. (1952). Idea de la Historia. Fondo de Cultura Económica.

de Swaan, A. (2015). The Killing Compartments. The Mentality of Mass Murder. Yale University Press.

El-Hai, J. (2015). El nazi y el psiquiatra. Ariel.

Fraser, N. (2013). We Love Impunity: The Case of The Act of Killing. Film Quarterly, 67(2), 21-24. https://doi.org/10.1525/fq.2014.67.2.21

Fraser, N. (2014). The Act of Killing: Don't give an Oscar to this snuff movie. https://www. theguardian.com/commentisfree/2014/feb/23/act-of-killing-dont-give-oscar-snuffmovie-indonesia

Hatzfeld, J. (2004). Una temporada de machetes. Anagrama.

Jablonka, I. (2017). Nueva memoria para una nueva historia. En I. Jablonka \& A. Wieviorka (Eds.), Nuevas perspectivas sobre la Shoá. Universidad Nacional de Quilmes Editorial.

LaCapra, D. (2005). Escribir la historia, escribir el trauma. Nueva Visión. 
Lanzmann, C. (2011). La liebre de la Patagonia. Seix Barral.

Metz, J. (2012). Reading the victimizer: Towards an ethical practice of figuring the traumatic moment in Holocaust literature. Textual Practice, 26 (6), 1021-1043. https://doi.org/10. 1080/0950236X.2012.727016

Oppenheimer, J. (2012). Perpetrators' Testimony and the Restoration of Humanity: S21, Rithy Panh. En Joram ten Brink \& J. Oppenheimer (Eds.), Killer Images. Documentary Film, Memory and the Performance of Violence. Wallflower.

Oppenheimer, J., \& Uwemedimo, M. (2012). Show of Force. A cinema-séance of power and Violence in Sumatra's plantation belt. En J. Oppenheimer \& J. ten Brink (Eds.), Killer Images. Documentary Film, Memory and the Performance of Violence (pp. 287-310). Wallflower. https://onlinelibrary.wiley.com/doi/abs/10.1111/j.1467-8705.2009.01851.x

Panh, R., \& Bataille, C. (2013). La eliminación. Anagrama.

Plantinga, C. (2009). The Philosophy of Errol Morris: Ten Lessons. En W. Rothman (Ed.), Three Documentary Filmmakers. Errol Morris, Ross McElwee, Jean Rouch. SUNY.

Robinson, G. (2018). The Killing Season. Princeton University Press.

Roosa, J. (2006). Pretext for Mass Murder. The September 30th Movement and Suharto's Coup d'Etat in Indonesia. The University of Wisconsin Press.

Taylor, C. (2006). Imaginarios sociales modernos. Paidós.

Waller, J. (2007). Becoming Evil. How Ordinary People Commit Genocide and Mass Killing. Oxford University Press.

Wieviorka, A. (2006). The Era of Witness. Cornell University Press.

Williams, T., \& Buckley-Zistel, S. (Eds.). (2018). Perpetrators and Perpetration of Mass Violence. Action, Motivations and Dynamics. Routledge.

Winston, B. (1988). The Tradition of the Victim in Griersonian Documentary. En A. Rosenthal (Ed.), New Challenges for Documentary (pp. 269-287). University of California Press.

Zimbardo, P. (2008). El efecto Lucifer. Paidós.

Zylberman, L. (2015). ¿Una película sobre el olvido? Sobre The act of killing de Joshua Oppenheimer. TOMA UNO, 4, 57-70.

Zylberman, L. (2016). Una aproximación a la construcción del mal en el díptico documental de Joshua Oppenheimer sobre Indonesia. Cuadernos de Marte, 0(10), 149-172.

Zylberman, L. (2018). Cine Documental y Genocidio: Hacia un abordaje integral. Significação: Revista de Cultura Audiovisual, 45(50), 223-238. https://doi.org/10.11606/issn.2316-7114. sig.2018.144075

Abstract: This article is part of an investigation about the representation of genocides in documentary cinema, in this instance I will be discuss about how the memory of the perpetrators has been presented. To do this, some background and problems about the subject will first be briefly reviewed; secondly, I will comment the representation strategies 
employed that I suggest to analyze the representation of the perpetrators; finally, I will focus on the participatory mode trough the analysis of the documentaries The Act of Killing (Joshua Oppenheimer, 2012) and The Look of Silence (Joshua Oppenheimer, 2014). There, in addition to think about the characteristics of this modality, we will analyze the memory that this strategy allows to set in motion.

Keywords: Documentary Cinema - genocide - perpetrators - modes - violence

Resumo: Este trabalho faz parte de uma investigação sobre a representação de genocídios no cinema documental, neste caso, será investigado sobre como a memória dos autores foi apresentada. Para fazer isso, alguns antecedentes e problemas sobre o assunto serão primeiro revisados brevemente; segundo, revisaremos as estratégias de representação empregadas que sugerimos para analisar a representação do autor; finalmente, focamos na modalidade participativa baseada nos documentários The Act of Killing (Joshua Oppenheimer, 2012) e The Look of Silence (Joshua Oppenheimer, 2014). Lá, além de pensar nas características dessa modalidade, analisaremos a memória que essa estratégia permite acionar.

Palavras chave: Cinema Documental - genocídio - intérpretes - modos - violência

[Las traducciones de los abstracts fueron supervisadas por el autor de cada artículo] 